\title{
Sách tác giả Phenikaa Uni biên tập xuất bản và có mặt trên Google Books
}

\author{
Nguyễn Thanh Huyền \\ Trung tâm ISR \\ Trường Đại học Phenikaa
}

Hà Nội, ngày 7 tháng 12 năm 2020

Sau 16 tháng chuẩn bị, cuốn chuyên khảo do TS Vương Quân Hoàng, Giám đốc Trung tâm ISR, Trường Đại học Phenikaa, có tựa đề Entrepreneurial Finance at the Dawn of Industry 4.0, đã hoàn tất vào tháng 6 năm 2020.

Tiếp theo quá trình sản xuất, tới ngày 4 tháng 12 , cuốn sách đã được xuất bản, ISBN 978-3-03943-597-5 (bìa cứng). Đồng thời, bản điện tử cũng đã online trên Google Books tại địa chỉ: https://books.google.com/books?id=uMIMEAAAQBAJ

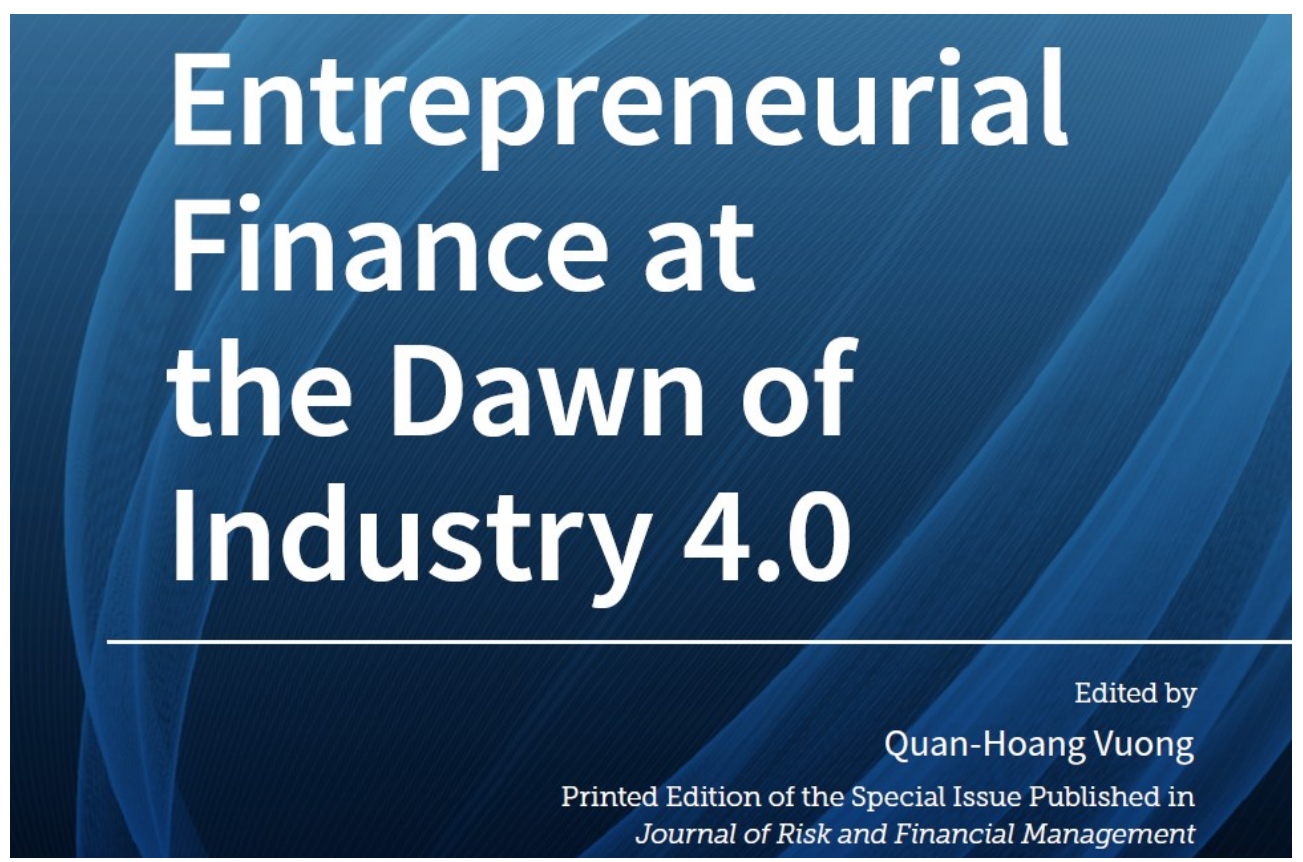

https://books.google.com/books?id=uMIMEAAAQBAJ

Bản in bìa cứng cuốn sách sẽ có thể đặt qua hệ thống thương mại điện tử Amazon tại địa chỉ: https://www.amazon.com/dp/3039435975/ hoặc trang web của cuốn sách tại địa chỉ: https://www.mdpi.com/books/pdfview/book/3167. Cuốn sách đánh dấu hai năm liên 
tiếp Trung tâm ISR có sách biên tập xuất bản quốc tế. Hơn một năm trước, cuốn The Vietnamese Social Sciences at a Fork in the Road (ISBN-13 : 978-3110686074), đã được De Gruyter xuất bản, và đang có mặt trên Amazon:

https://www.amazon.com/dp/3110686074/.

\section{References}

Quan-Hoang Vuong. (2020). Entrepreneurial Finance at the Dawn of Industry 4.0. Basel, Switzerland: MDPI AG.

Quan-Hoang Vuong, and Trung Tran. (2019). The Vietnamese Social Sciences at a Fork in the Road. Warsaw, Poland: De Gruyter (Imprint: Sciendo). 